\title{
Interactive comment on "Pivotal role of the North African Dipole Intensity (NAFDI) on alternate Saharan dust export over the North Atlantic and the Mediterranean, and relationship with the Saharan Heat Low and mid-latitude Rossby waves" by E. Cuevas et al.
}

E. Cuevas et al.

ecuevasa@aemet.es

Received and published: 18 May 2016

Attached is proposed a small change in the the vertical profile of a barotropic Rossby wave in the absence of vertically-sheared zonal flow.

Please also note the supplement to this comment:

http://www.atmos-chem-phys-discuss.net/acp-2016-287/acp-2016-287-AC3supplement.pdf 
Interactive comment on Atmos. Chem. Phys. Discuss., doi:10.5194/acp-2016-287, 2016.

Interactive comment 